BMJ Open

Diabetes

Research

\& Care

\section{Amyloid-related protein changes associated with dementia differ according to severity of hypoglycemia}

To cite: Moin ASM, Kahal H, Al-Qaissi A, et al. Amyloid-related protein changes associated with dementia differ according to severity of hypoglycemia. BMJ Open Diab Res Care 2021;9:e002211. doi:10.1136/ bmjdrc-2021-002211

- Supplemental material is published online only. To view, please visit the journal online (http://dx.doi.org/10.1136/ bmjdrc-2021-002211).

SLA and AEB are joint senior authors.

Received 13 February 2021 Revised 1 April 2021 Accepted 4 April 2021

Check for updates

(C) Author(s) (or their employer(s)) 2021. Re-use permitted under CC BY-NC. No commercial re-use. See rights and permissions. Published by BMJ.

${ }^{1}$ Diabetes Research Center, Qatar Biomedical Research Institute, Doha, Qatar ${ }^{2}$ Diabetes and Metabolism, Hull York Medical School, Hull, UK ${ }^{3}$ Diabetes and Metabolism, Leeds Medical School, Leeds, UK

${ }^{4}$ Royal College of Surgeons in Ireland and Medical University of Bahrain, Busaiteen, Bahrain

Correspondence to Dr Alexandra E Butler; aeb91011@gmail.com

\section{ABSTRACT}

Introduction Hypoglycemia in type 2 diabetes (T2D) may increase risk for Alzheimer's disease (AD), but no data on changes in AD-related proteins with differing degrees of hypoglycemia exist. We hypothesized that milder prolonged hypoglycemia would cause greater AD-related protein changes versus severe transient hypoglycemia.

Research design and methods Two prospective casecontrol induced hypoglycemia studies were compared: study 1 , hypoglycemic clamp to $2.8 \mathrm{mmol} / \mathrm{L}(50 \mathrm{mg} / \mathrm{dL})$ for 1 hour in 17 subjects (T2D $(n=10)$, controls $(n=7))$; study 2 , hypoglycemic clamp to $2.0 \mathrm{mmol} / \mathrm{L}(36 \mathrm{mg} / \mathrm{dL}$ ) undertaken transiently and reversed in 46 subjects (T2D $(n=23)$, controls $(n=23))$. Blood sampling at baseline, hypoglycemia and 24-hour post-hypoglycemia, with proteomic analysis of amyloid-related proteins performed.

Results In control subjects, the percentage change from baseline to hypoglycemia differed between study 1 and study 2 for 5 of 11 proteins in the AD-related panel: serum amyloid A1 (SAA1) ( $p=0.009$ ), pappalysin (PAPPA) $(p=0.002)$, apolipoprotein $E 2(p=0.02)$, apolipoprotein $E 3$ $(p=0.03)$ and apolipoprotein $E 4(p=0.02)$. In controls, the percentage change from baseline to 24 hours differed between studies for two proteins: SAA1 $(p=0.003)$ and PAPPA ( $p=0.004)$; however, after Bonferroni correction only SAA1 and PAPPA remain significant. In T2D, there were no differential protein changes between the studies.

Conclusions The differential changes in AD-related proteins were seen only in control subjects in response to iatrogenic induction of hypoglycemic insults of differing length and severity and may reflect a protective response that was absent in subjects with T2D. Milder prolonged hypoglycemia caused greater AD-related protein changes than severe acute hypoglycemia in control subjects.

Trial registration numbers NCT02205996, NCT03102801.

\section{INTRODUCTION}

Along with the well-documented macrovascular and microvascular complications of diabetes, a marked increase in dementia in patients with type 2 diabetes (T2D) is also well recognized. ${ }^{1-4}$ Alzheimer's disease $(\mathrm{AD})$, the most common form of dementia, comprises $60 \%-80 \%$ of all dementia cases. ${ }^{5}$ Epidemiological evidence indicates that patients with T2D are at increased risk for developing

\section{Significance of this study}

What is already known about this subject?

- We recently reported that severe, transient iatrogenic induction of hypoglycemia has a detrimental effect on Alzheimer's disease (AD)-associated proteins and that the increased risk subjects with type 2 diabetes (T2D) have for development of AD may be exacerbated by hypoglycemia.

- Prior to this report, there had been no previous studies looking at AD-related proteins in plasma in response to hypoglycemia.

What are the new findings?

- Milder but prolonged hypoglycemia leads to greater changes in AD-related proteins when compared with severe transient hypoglycemia.

- Interestingly, however, the differential changes were seen only in control subjects, suggesting that control subjects are able to mount a protective robust antiinflammatory response to counteract the enhanced stress of prolonged hypoglycemia, but that subjects with T2D cannot.

How might these results change the focus of research or clinical practice?

- AD protein responses to hypoglycemia at differing glycemic control points may advise on the optimum diabetes control to address $A D$ risks, with further work focused on glucose variability and $A D$ protein modulation.

- Optimal diabetes control using therapeutic agents that do not cause hypoglycemia would appear to be the best treatment strategy to address $A D$.

AD ${ }^{6-8}$ Elevation in key circulating AD-related proteins, such as plasma amyloid precursor protein (APP), have been reported in association with $\mathrm{AD}$, with levels of APP showing a positive trend with increasing cognitive impairment. $^{910}$

Optimal management of T2D involving tighter glucose control increases the risk for, and frequency of, hypoglycemic episodes. Hypoglycemia has been directly linked to 
cognitive dysfunction, potentially increasing the risk of dementia. ${ }^{11}$

We previously undertook a clinical interventional study, specifically designed to mimic the physiological responses to hypoglycemia seen clinically in patients with diabetes ${ }^{12}$ and reported that a severe hypoglycemic episode had detrimental effects on circulating AD-related proteins in patients with $\mathrm{T} 2 \mathrm{D},{ }^{13}$ thus providing a mechanistic link between T2D-associated hypoglycemia and $\mathrm{AD}$. It is, however, not known whether a differing length and degree of hypoglycemic insult would cause similar perturbations in plasma AD-related protein levels.

We hypothesized that milder prolonged hypoglycemia would lead to greater changes in AD-related proteins when compared with a severe transient hypoglycemic episode. To this end, we compared amyloid-related proteins levels following a milder prolonged iatrogenicinduced hypoglycemic insult (study 1) with an acute severe iatrogenic-induced hypoglycemia (study 2) in subjects with and without T2D.

\section{RESEARCH DESIGN AND METHODS}

\section{Study design}

Study 1 design

A prospective case-control study in adult subjects with T2D $(n=10)$ and control subjects $(n=7)$; all but one of the subjects were Caucasian (one subject with T2D was South Asian), aged 40-53 years. As previously described, ${ }^{14}$ a hypoglycemic clamp to $2.8 \mathrm{mmol} / \mathrm{L}(50 \mathrm{mg} / \mathrm{dL})$ was undertaken for 1 hour.

Blood sampling was performed at baseline, at hypoglycemia after 1 hour and 24 hours post-hypoglycemia.

\section{Study 2 design}

A prospective case-control study was performed in 46 subjects, adult subjects with T2D $(\mathrm{n}=23)$ and control subjects $(n=23)$; all subjects were Caucasian, aged 40-70 years. As previously described, ${ }^{12}$ a hypoglycemic clamp to $2.0 \mathrm{mmol} / \mathrm{L}(36 \mathrm{mg} / \mathrm{dL})$ was undertaken transiently and then immediately reversed. Blood sampling was performed at baseline, at the point of hypoglycemia and at 24 hours posthypoglycemia.

\section{Study subjects}

Both studies were undertaken at the Diabetes Centre at Hull Royal Infirmary. Inclusion criteria for the T2D cohort in both studies included a duration of diabetes $<10$ years and maintenance on a stable dose of medication (metformin, statin and/or ACE inhibitor/angiotensin receptor blocker) over the prior 3 months; no glycemic control medications other than metformin were allowed; hemoglobin A1c (HbAlc) levels $<10 \%(86 \mathrm{mmol} / \mathrm{mol})$ ); no history of either hypoglycemic unawareness or hypoglycemia within a 3-month period. In the control group, diabetes was excluded with an oral glucose tolerance test and subjects were not on any medication nor had any known medical condition. All subjects had a body mass index (BMI) between 18 and $49 \mathrm{~kg} / \mathrm{m}^{2}$, and all had normal renal and hepatic biochemical indices and no history of cancer nor any contraindication to insulin infusion to achieve hypoglycemia (ischemic heart disease, epilepsy, seizure history, drop attacks, history of adrenal insufficiency and treated hypothyroidism). All subjects had a medical history, clinical examination, routine blood tests and an ECG performed.

\section{Biochemical markers}

As previously described, ${ }^{12-14}$ blood samples were separated immediately by centrifugation at $2000 \mathrm{~g}$ for $15 \mathrm{~min}$ at $4^{\circ} \mathrm{C}$, and the aliquots were stored at $-80^{\circ} \mathrm{C}$, within $30 \mathrm{~min}$ of blood collection, until batch analysis. Fasting plasma glucose, total cholesterol and triglycerides were measured enzymatically using a Beckman AU 5800 analyser (Beckman-Coulter, High Wycombe, UK).

\section{SOMA-scan assay}

As previously described, ${ }^{13}$ the SOMAscan assay used to quantify proteins was performed on an in-house Tecan Freedom EVO liquid handling system (Tecan Group, Maennedorf, Switzerland) using buffers and SOMAmers from the SOMAscan HTS Assay 1.3K plasma kit (SomaLogic, Boulder, Colorado, USA) according to manufacturer's instructions and as described previously. ${ }^{1516}$

\section{Data processing and analysis}

Initial relative fluorescent units (RFUs) were obtained from microarray intensity images using the Agilent Feature Extraction Software (Agilent, Santa Clara, California, USA). Raw RFUs were normalized and calibrated using the software pipeline provided by SomaLogic. This included (a) microarray hybridization normalization based on spiked-in hybridization controls, (b) plate-specific intensity normalization, (c) median signal normalization and (d) median calibrator scaling of single RFU intensities according to calibrator reference values. Samples with a high degree of hemolysis (Haptoglobin $\log \mathrm{RFU}<10$ ) were excluded from the analysis.

Statistical analyses were performed on $\log _{2}$ RFU values using R V.3.5.2 (R Foundation for Statistical Computing, Vienna, Austria) including base R package. Data handling and differential protein expression were analyzed using the autonomics and limma ${ }^{17}$ packages. For differential protein analysis, we applied limma models containing contrasts between timepoints, as well as contrasts between healthy patients and patients with diabetes at single timepoints. In both models, blocking by patient ID was performed to account for random effects. Batch effect correction was performed by adding batch as a covariate to the model. Limma obtained $\mathrm{p}$ values were corrected using the Benjamini-Hochberg method. ${ }^{18}$

\section{Statistical analysis}

Based on our previous study to detect a significant rise in APP in the control population, a sample size of seven patients was calculated giving $80 \%$ power to detect a mean increase of $18000 \mathrm{RFU}$ of APP, with a alpha error of $0.05 .{ }^{13}$ Data trends were visually evaluated for each 
Table 1 Demographic and biochemical parameters of control subjects and subjects with T2D included in study 1 and study 2

\begin{tabular}{|c|c|c|c|c|c|c|}
\hline & $\begin{array}{l}\text { Study } 1 \\
\text { controls }(n=7)\end{array}$ & $\begin{array}{l}\text { Study } 2 \\
\text { controls }(n=23)\end{array}$ & $P$ value & $\begin{array}{l}\text { Study 1 T2D } \\
(n=10)\end{array}$ & $\begin{array}{l}\text { Study } 2 \text { T2D } \\
(n=23)\end{array}$ & $P$ value \\
\hline Age (years) & $47 \pm 6$ & $60 \pm 10$ & 0.003 & $46 \pm 6$ & $64 \pm 8$ & $<0.0001$ \\
\hline $\operatorname{Sex}(M / F)$ & $4 \mathrm{M} / 3 \mathrm{~F}$ & $11 \mathrm{M} / 12 \mathrm{~F}$ & & $7 \mathrm{M} / 3 \mathrm{~F}$ & $12 \mathrm{M} / 11 \mathrm{~F}$ & \\
\hline BMI $\left(\mathrm{kg} / \mathrm{m}^{2}\right)$ & $29 \pm 4$ & $28 \pm 3$ & 0.640 & $36 \pm 7$ & $32 \pm 4$ & 0.03 \\
\hline Systolic BP (mm Hg) & $126 \pm 15$ & $122 \pm 8$ & 0.280 & $127 \pm 20$ & $132 \pm 8$ & 0.31 \\
\hline Diastolic BP (mm Hg) & $75 \pm 13$ & $75 \pm 6$ & 1.000 & $75 \pm 11$ & $81 \pm 7$ & 0.08 \\
\hline Duration of diabetes (years) & N/A & N/A & & $3.3 \pm 2.3$ & $4.5 \pm 2.2$ & 0.14 \\
\hline $\mathrm{HbA} 1 \mathrm{c}(\mathrm{mmol} / \mathrm{mol})$ & $33.6 \pm 2.9$ & $37.2 \pm 2.2$ & 0.004 & $49 \pm 12$ & $51 \pm 11$ & 0.62 \\
\hline $\mathrm{HbA1c}(\%)$ & $5.2 \pm 0.3$ & $5.6 \pm 0.2$ & 0.006 & $6.6 \pm 1.0$ & $6.8 \pm 1.0$ & 0.48 \\
\hline Total cholesterol (mmol/L) & $5.1 \pm 0.8$ & $4.8 \pm 0.77$ & 0.230 & $5.3 \pm 0.7$ & $4.2 \pm 1.0$ & 0.36 \\
\hline Triglyceride (mmol/L) & $1.2 \pm 0.5$ & $1.3 \pm 0.6$ & 0.540 & $1.7 \pm 0.8$ & $1.7 \pm 0.7$ & 0.96 \\
\hline CRP (mg/L) & $0.8 \pm 0.0$ & $5.1 \pm 10.3$ & 0.26 & $2.8 \pm 1.8$ & $3.1 \pm 2.9$ & 0.94 \\
\hline
\end{tabular}

Data are presented as mean $\pm 1 \mathrm{SD}$.

BMI, body mass index; BP, blood pressure; CRP, C reactive protein; F, female; HbA1c, hemoglobin A1c; M, male; T2D, type 2 diabetes.

parameter and non-parametric tests were applied on data that violated the assumptions of normality when tested using the Kolmogorov-Smirnov test. Comparison between groups was performed at each timepoint using Student's t-test. Within-group comparisons of changes between timepoints were compared using Student's t-test. To account for multiple comparisons, the significance level cut-off was estimated using the Bonferroni method and a value of 0.0045 was considered statistically significant. The sample size was too small to adjust for baseline covariates. To rule out underlying association of age, $\mathrm{BMI}$ and $\mathrm{HbA1c}$ with the $\mathrm{AD}$ proteins, one-to-one correlation was estimated for age, BMI and HbAlc with all the AD proteins for each study using Pearson's correlation. Statistical analysis was performed using GraphPad Prism (San Diego, California, USA) and STATA V.16 (StataCorp, College Station, Texas, USA).

\section{RESULTS}

Study 1 included 17 subjects (T2D $(\mathrm{n}=10)$ and control $(\mathrm{n}=7)$ ). Study 2 included 46 subjects (T2D $(\mathrm{n}=23)$ and control $(n=23)$ ). Demographic and biochemical data for the control subjects and subjects with T2D included in study 1 and study 2 are shown in table 1 . Subjects did not differ in their medication between studies.

Both control subjects $(p=0.003)$ and subjects with T2D $(\mathrm{p}<0.0001)$ in study 2 were older than their study 1 counterparts. BMI did not differ between studies for controls. For subjects with T2D, BMI was greater in study $1(\mathrm{p}<0.03)$. HbAlc was higher in study 2 versus study 1 control subjects $(\mathrm{p}=0.006)$, in keeping with the reported association of increasing HbAlc with age, ${ }^{19}$ although was still well within the normal non-diabetic range in both cohorts. Association between age and BMI and each of the AD-related proteins for each study were estimated and no correlations were found, suggesting that neither age nor BMI were confounding factors between the studies. HbA1c did not correlate with any of the AD-related proteins for either study (online supplemental tables 1 and 2).

Total cholesterol, triglycerides, blood pressure and CRP, as a marker for inflammation, did not differ between control groups or between T2D groups (table 1).

Eleven AD-related proteins were included in the analysis: amyloid precursor protein (APP), amyloid $\mathrm{P}$ component (APCS), serum amyloid A1 (SAA1), pappalysin (PAPPA), microtubule-associated protein tau (MAPT), apolipoprotein A1 (APOA1), noggin, apolipoprotein E (APOE), apolipoprotein E2 (APOE2), apolipoprotein E3 (APOE3) and apolipoprotein E4 (APOE4).

\section{Differences between T2D and controls at baseline in each study}

At baseline, levels of all 11 AD-related proteins were comparable between T2D and controls in study $1(\mathrm{p}=\mathrm{ns})$.

At baseline, only APP differed between T2D and controls, being elevated in T2D in study $2(\mathrm{p}=0.02)$ as previously reported. ${ }^{13}$

Because study 1 and study 2 were performed at different times and analysed separately, and not as part of a single study, it is not possible to directly compare protein levels between studies. Therefore, relative change, rather than absolute change, in proteins was undertaken to account for assay differences. For the 10 AD-related proteins where there was no difference between T2D and controls at baseline in their respective studies, baseline protein levels were normalized to 1 to compare the per cent change from baseline to subsequent timepoints in both studies. 

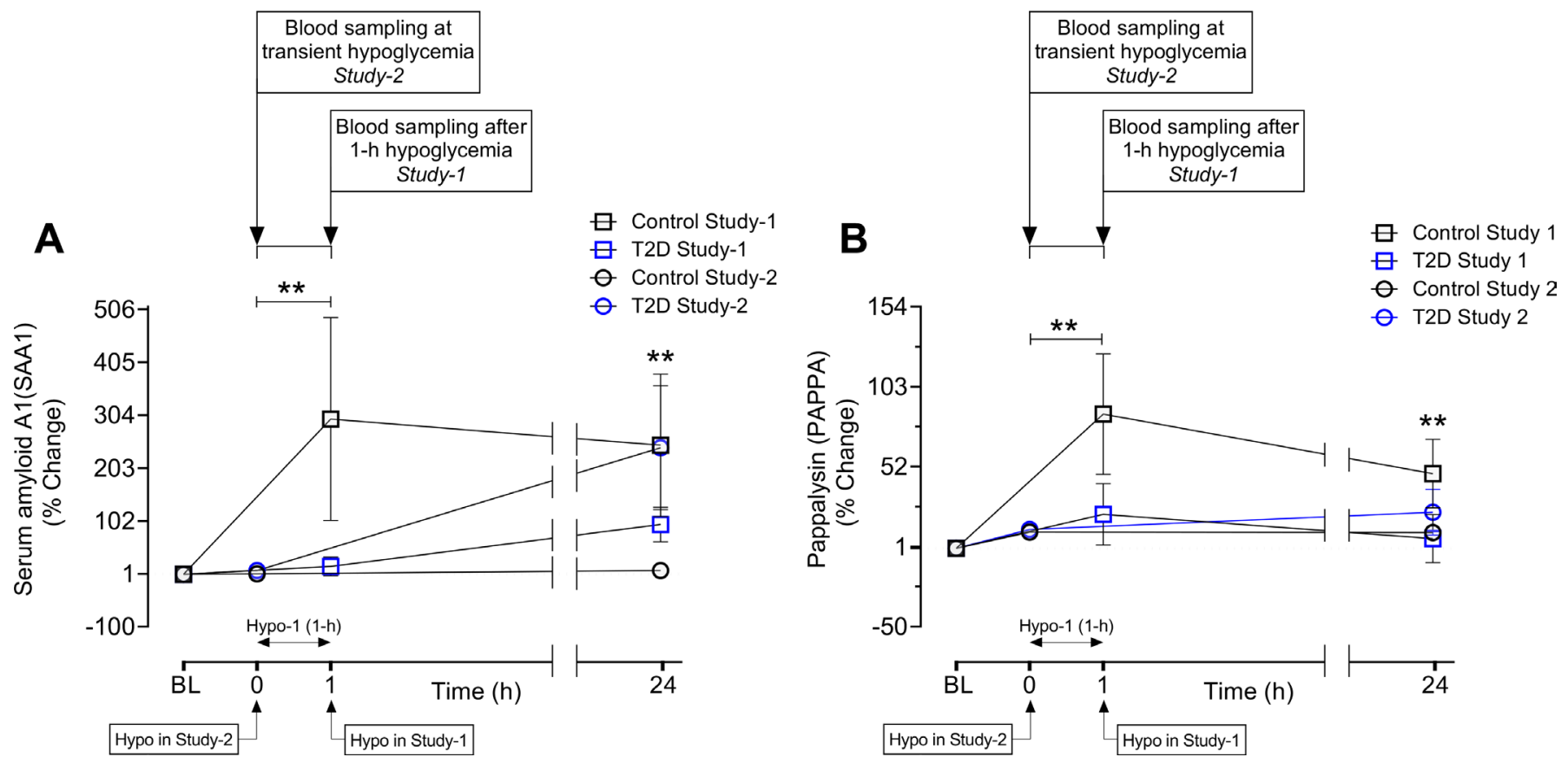

Figure 1 Per cent (\%) changes of Alzheimer's disease (AD)-related proteins in response to hypoglycemia in two different prospective studies in control subjects and subjects with type 2 diabetes (T2D). Line graphs showing changes as percentage of two AD-related proteins, serum amyloid A1 (SAA1) (A) and pappalysin (PAPPA) (B) from baseline to hypoglycemia and to 24 hours posthypoglycemia in study 1 (open white square, control and open blue square, T2D) and study 2 (open white circle, control and open blue circle, T2D). Baseline protein levels were normalized to 1 to show the $\%$ change from baseline to subsequent timepoints. SAA1 and PAPPA showed a significant differential percentage change from baseline to hypoglycemia and from baseline to 24 hours in controls. There were no differential percentage changes in T2D for SAA1 or PAPPA in any of the studies. Two-way arrows in the graphs indicate the duration of hypoglycemia for study 1 . Data were present here as mean $\%$ change of proteins \pm SEM. ${ }^{* *} \mathrm{p}<0.01$. BL, baseline; Hypo, hypoglycemia.

\section{Differences between studies in per cent change from baseline Baseline to hypoglycemia}

In control subjects, the percentage change from baseline to hypoglycemia differed between study 1 and study 2 for 6 of the 11 proteins included in the panel: SAA1 $(\mathrm{p}=0.017)$,
PAPPA $(\mathrm{p}=0.004) \quad$ (figure 1A,B); APOE2 $(\mathrm{p}=0.015)$, APOE3 ( $\mathrm{p}=0.03)$ and APOE4 $(\mathrm{p}=0.01)$ (figure $2 \mathrm{~A}-\mathrm{C}$ and table 2) and APOE ( $\mathrm{p}=0.04)$ (figure 3B). To account for multiple comparisons, significance cut-off was adjusted using Bonferroni correction, which yielded a $\mathrm{p}$ value
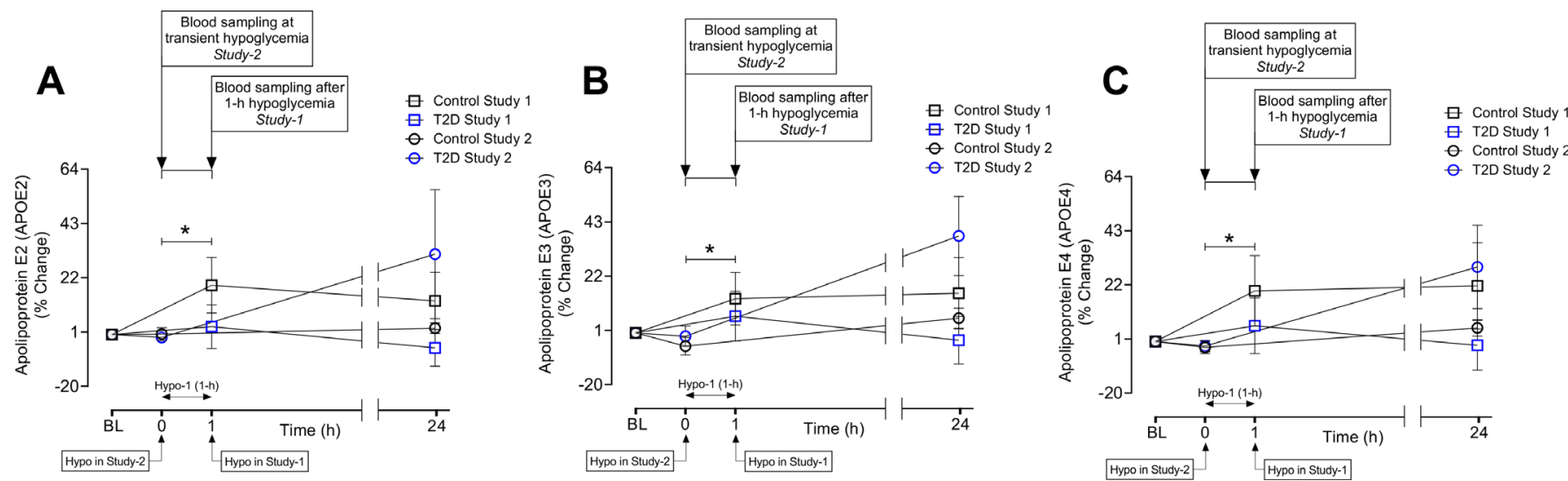

Figure 2 Per cent (\%) changes of apolipoprotein Es (APOEs) in response to hypoglycemia in two different prospective studies in control subjects and subjects with type 2 diabetes (T2D). Line graphs showing changes as percentage of three Alzheimer's disease (AD)-related apolipoproteins, APOE2 (A), APOE3 (B) and APOE4 (C) from baseline to hypoglycemia and to 24 hours posthypoglycemia in study 1 (open white square, control and open blue square, T2D) and study 2 (open white circle, control and open blue circle, T2D). Baseline protein levels were normalized to 1 to show the $\%$ change from baseline to subsequent timepoints. APOE2, APOE3 and APOE4 showed a significant differential percentage change from baseline to hypoglycemia in control but not in T2D. There were no differential percentage changes of the apolipoproteins 24 hours posthypoglycemia compared with baseline both in control and in T2D. Two-way arrows in the graphs indicate the duration of hypoglycemia for study 1 . Data were present here as mean $\%$ change of proteins \pm SEM. ${ }^{*} \mathrm{P}<0.05$. BL, baseline; Hypo, hypoglycemia. 
Table 2 A comparison of the change in plasma protein levels of Alzheimer's disease (AD)-related proteins following a milder prolonged iatrogenic-induced hypoglycemic insult (study 1) with an acute severe iatrogenic-induced hypoglycemia (study 2) in subjects with and without T2D

\begin{tabular}{|c|c|c|c|c|c|c|c|c|}
\hline \multirow[t]{2}{*}{$\begin{array}{l}\text { Proteins } \\
\text { ( } \% \text { change) }\end{array}$} & \multicolumn{2}{|c|}{$\begin{array}{l}\text { Control } \\
\text { (baseline to } \\
\text { hypoglycemia) }\end{array}$} & \multicolumn{2}{|c|}{$\begin{array}{l}\text { Control } \\
\text { (baseline to } 24 \text { hours) }\end{array}$} & \multicolumn{2}{|c|}{$\begin{array}{l}\text { T2D } \\
\text { (baseline to } \\
\text { hypoglycemia) }\end{array}$} & \multicolumn{2}{|c|}{$\begin{array}{l}\text { T2D } \\
\text { (baseline to } 24 \text { hours) }\end{array}$} \\
\hline & Study 1 & Study 2 & Study 1 & Study 2 & Study 1 & Study 2 & Study 1 & Study 2 \\
\hline APP & $\begin{array}{l}-26.1 \pm 21.2 \\
p=0.07\end{array}$ & $124.0 \pm 42.0$ & $\begin{array}{l}11.0 \pm 31.0 \\
p=0.53\end{array}$ & $-9.4 \pm 15.2$ & $\begin{array}{l}41.4 \pm 36.2 \\
p=0.36\end{array}$ & $83.7 \pm 25.7$ & $\begin{array}{l}15.2 \pm 20.8 \\
p=0.9\end{array}$ & $23.9 \pm 43.2$ \\
\hline APCS & $\begin{array}{l}1.9 \pm 4.5 \\
p=0.06\end{array}$ & $-6.5 \pm 1.9$ & $\begin{array}{l}-3.7 \pm 5.6 \\
p=0.84\end{array}$ & $-4.5 \pm 1.6$ & $\begin{array}{l}1.8 \pm 9.3 \\
p=0.9\end{array}$ & $0.9 \pm 2.6$ & $\begin{array}{l}-3.2 \pm 7.5 \\
p=0.5\end{array}$ & $19.3 \pm 21.5$ \\
\hline SAA1 & $\begin{array}{l}289.0 \pm 229.2 \\
p=0.017\end{array}$ & $-0.8 \pm 3.8$ & $\begin{array}{l}246.5 \pm 136.0 \\
p=0.003\end{array}$ & $7.2 \pm 5.9$ & $\begin{array}{l}15.2 \pm 18.0 \\
p=0.56\end{array}$ & $7.2 \pm 4.2$ & $\begin{array}{l}95.3 \pm 32.8 \\
p=0.42\end{array}$ & $241.8 \pm 118.5$ \\
\hline PAPPA & $\begin{array}{l}83.3 \pm 45.4 \\
p=0.004\end{array}$ & $10.3 \pm 3.3$ & $\begin{array}{l}47.6 \pm 21.8 \\
p=0.004\end{array}$ & $9.9 \pm 2.2$ & $\begin{array}{l}21.6 \pm 19.5 \\
p=0.48\end{array}$ & $12.0 \pm 2.4$ & $\begin{array}{l}6.2 \pm 15.4 \\
p=0.49\end{array}$ & $23.0 \pm 14.6$ \\
\hline MAPT & $\begin{array}{l}10.4 \pm 19.4 \\
p=0.63\end{array}$ & $17.7 \pm 6.1$ & $\begin{array}{l}8.0 \pm 23.1 \\
p=0.72\end{array}$ & $3.4 \pm 2.5$ & $\begin{array}{l}33.5 \pm 16.5 \\
p=0.22\end{array}$ & $17.4 \pm 4.7$ & $\begin{array}{l}13.3 \pm 8.8 \\
p=0.97\end{array}$ & $14.2 \pm 14.0$ \\
\hline APOA1 & $\begin{array}{l}12.5 \pm 8.6 \\
p=0.28\end{array}$ & $2.3 \pm 4.2$ & $\begin{array}{l}-0.4 \pm 5.0 \\
p=0.87\end{array}$ & $0.6 \pm 3.1$ & $\begin{array}{l}6.0 \pm 7.5 \\
p=0.97\end{array}$ & $6.4 \pm 5.2$ & $\begin{array}{l}-10.2 \pm 6.7 \\
p=0.45\end{array}$ & $15.3 \pm 22.2$ \\
\hline NOG & $\begin{array}{l}36.0 \pm 45.2 \\
p=0.93\end{array}$ & $39.0 \pm 13.6$ & $\begin{array}{l}14.5 \pm 26.4 \\
p=0.25\end{array}$ & $-4.9 \pm 4.9$ & $\begin{array}{l}61.8 \pm 31.8 \\
p=0.13\end{array}$ & $24.0 \pm 8.5$ & $\begin{array}{l}24.7 \pm 26.5 \\
p=0.37\end{array}$ & $2.2 \pm 11.7$ \\
\hline APOE & $\begin{array}{l}26.0 \pm 14.4 \\
p=0.04\end{array}$ & $-4.8 \pm 6.7$ & $\begin{array}{l}26.0 \pm 13.1 \\
p=0.18\end{array}$ & $5.1 \pm 7.4$ & $\begin{array}{l}11.2 \pm 17.1 \\
p=0.68\end{array}$ & $4.4 \pm 8.0$ & $\begin{array}{l}1.2 \pm 8.4 \\
p=0.25\end{array}$ & $40.7 \pm 22.2$ \\
\hline APOE2 & $\begin{array}{l}20.6 \pm 12.6 \\
p=0.01\end{array}$ & $0.2 \pm 2.5$ & $\begin{array}{l}13.0 \pm 11.0 \\
p=0.14\end{array}$ & $2.5 \pm 2.0$ & $\begin{array}{l}3.1 \pm 8.5 \\
p=0.5\end{array}$ & $-1.1 \pm 1.7$ & $\begin{array}{l}-5.1 \pm 7.1 \\
p=0.34\end{array}$ & $31.1 \pm 25.0$ \\
\hline APOE3 & $\begin{array}{l}14.6 \pm 12.0 \\
p=0.03\end{array}$ & $-5.1 \pm 3.4$ & $\begin{array}{l}15.4 \pm 13.8 \\
p=0.35\end{array}$ & $5.7 \pm 3.9$ & $\begin{array}{l}6.5 \pm 9.7 \\
p=0.38\end{array}$ & $-1.3 \pm 4.0$ & $\begin{array}{l}-2.8 \pm 9.2 \\
p=0.1\end{array}$ & $37.6 \pm 15.3$ \\
\hline APOE4 & $\begin{array}{l}22.2 \pm 16.0 \\
p=0.01\end{array}$ & $-2.3 \pm 2.3$ & $\begin{array}{l}21.7 \pm 16.7 \\
p=0.13\end{array}$ & $5.3 \pm 3.2$ & $\begin{array}{l}6.1 \pm 10.7 \\
p=0.32\end{array}$ & $-1.7 \pm 2.2$ & $\begin{array}{l}-1.4 \pm 9.6 \\
p=0.24\end{array}$ & $29.0 \pm 16.2$ \\
\hline
\end{tabular}

Per cent change from baseline to hypoglycemia and from baseline to 24 hours are shown for study 1 and study 2 , as well as Students' ttests of the comparison of percentage change between studies.

$P$ values in bold/italics indicate $p<0.01$.

APCS, amyloid P component; APOA1, apolipoprotein A1; APOE2, apolipoprotein E2; APOE3, apolipoprotein E3; APOE, apolipoprotein E; APOE4, apolipoprotein E4; APP, amyloid precursor protein; BL, baseline; MAPT, microtubule-associated protein tau; NOG, noggin; PAPPA, pappalysin; SAA1, serum amyloid A1; T2D, type 2 diabetes.

cut-off of 0.0045 . On application of this cut-off, only PAPPA remained significant.

For SAA1, the percentage change increase in controls in milder prolonged hypoglycemia (study 1) was marked, whereas there was minimal percentage decrease in response to severe acute hypoglycemia (study 2) (SAA1: $289.0 \pm 229.2$ vs $-0.8 \pm 3.8 \%$ change of SAA1 from baseline, controls study 1 vs study $2, \mathrm{p}=0.017$ ) (figure $1 \mathrm{~A}$ ).

Likewise, while PAPPA and APOE2 increased in response to hypoglycemia in both studies, the percentage change increase in controls was marked in response to milder prolonged hypoglycemia (study 1 ) and much less so in response to acute severe hypoglycemia (study 2) (PAPPA $83.3 \pm 45.4$ vs $10.3 \pm 3.3 \%$ change of PAPPA from baseline in control, controls study 1 vs study $2, \mathrm{p}=0.004$ (figure 1B); APOE2: $20.6 \pm 12.6$ vs $0.2 \pm 2.5 \%$ change of
APOE2 from baseline, controls study 1 vs study 2, $\mathrm{p}=0.01$ ) (figure 2A).

For APOE, APOE3 and APOE4, there was a percentage change increase in response to milder prolonged hypoglycemia, but a percentage change decrease in response to acute severe hypoglycemia (APOE: 26.0 $\pm 14.4 \mathrm{vs}$ $-4.8 \pm 6.7 \%$ change of APOE from baseline, controls study 1 vs study 2, $\mathrm{p}=0.04$; APOE3: $14.6 \pm 12.0$ vs $-5.1 \pm 3.4$ $\%$ change of APOE3 from baseline, controls study 1 vs study 2, $\mathrm{p}=0.03$; APOE4: $22.2 \pm 16.0 \mathrm{vs}-2.3 \pm 2.3 \%$ change of APOE4 from baseline, controls study 1 vs study 2, $\mathrm{p}=0.01$ ) (figures $2 \mathrm{~B}, \mathrm{C}$ and $3 \mathrm{~B}$ ).

For study 1, MAPT and NOG correlated $(\mathrm{r}=0.8)$, APOE correlated with APOE3 and APOE4 ( $\mathrm{r}=0.8$ and 0.8, respectively), APOE3 correlated with APOE2 and APOE4 $(\mathrm{r}=0.97$ and 0.8 , respectively). For study 2, MAPT and 

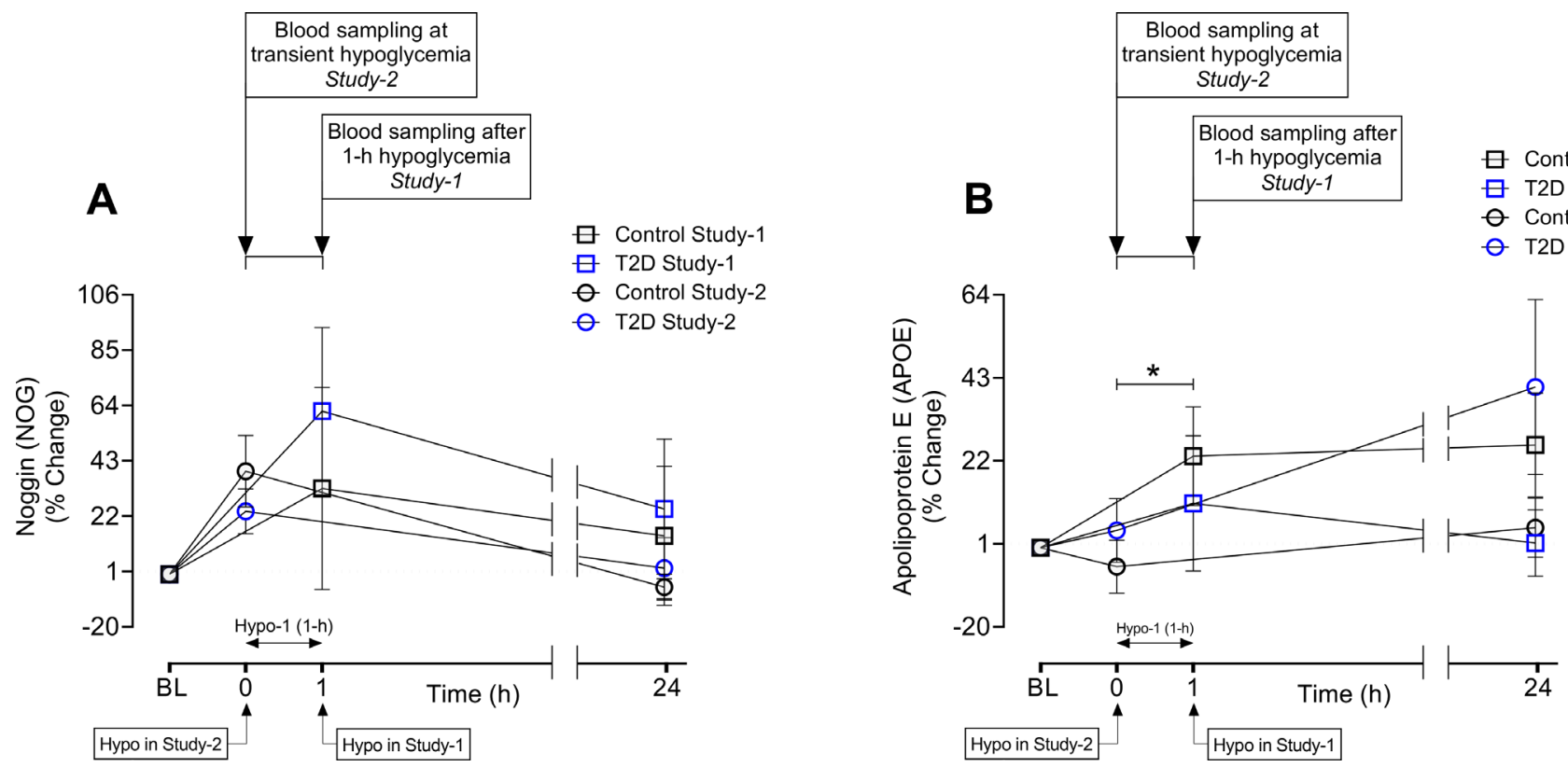

Figure 3 Line graphs showing changes as percentage of Alzheimer's disease (AD)-related protein, noggin (NOG) (A) and APOE (B) in control and type 2 diabetes (T2D) in two different prospective studies. Two-way arrows in the graphs indicate the duration of hypoglycemia for study 1 . Data were present here as mean $\%$ change of proteins $\pm S E M$. BL, baseline; Hypo, hypoglycemia. ${ }^{*} \mathrm{p}<0.05$.

APP $(\mathrm{r}=0.5)$ and NOG and APP correlated $(\mathrm{r}=0.6)$ : APOE correlated with APOE2, APOE3 and APOE4 (r=0.7, 0.8 and 0.9, respectively), APOE3 correlated with APOE2 and APOE4 ( $\mathrm{r}=0.8$ and 0.9 , respectively). Correlations were considered significant at $\mathrm{p}=0.0035$ to adjust for multiple comparisons.

For subjects with T2D, there were no significant percentage change differences from baseline to hypoglycemia for any of the above proteins between the two studies.

Interestingly, APP showed opposite effects in control subjects in response to hypoglycemia. While transient hypoglycemia (study 2) caused $124 \%$ increase $(124.0 \% \pm 42.0 \%)$ of APP, less-severe prolonged hypoglycemia (study 1) resulted in $\sim 26 \%$ decrease $(-26.1 \% \pm 21.2 \%)$ of APP in controls (figure $4 \mathrm{~A}$ ); this differential trend between the two studies was close to significance $(p=0.07)$. These data suggest a rapid clearance of APP levels within 1 hour of hypoglycemia in controls. In T2D, the $\%$ change of APP was increased in both studies ( 41\% in study 1 and $~ 84 \%$ in study 2$)$ in response to hypoglycemia relative to baseline; however, unlike in controls, less severe prolonged hypoglycemia did not result in a decreased percentage change of APP below baseline in T2D, suggesting a defect in APP clearance from blood in T2D $(41.4 \pm 36.2 \mathrm{vs}-26.1 \pm 21.2$ $\%$ change of APP in prolonged hypoglycemia in study 1 , T2D vs control, $\mathrm{p}=\mathrm{ns}$ ) (figure $4 \mathrm{~A}$ ). Other AD-related proteins, for example, APOA1 (figure 4B), APCS (figure 4C), MAPT (figure 4D) and Noggin (figure 3) did not differ in \% change from baseline to hypoglycemia for study 1 vs study 2 in either control or T2D cohorts.

\section{Baseline to 24 hours}

In control subjects, the percentage change from baseline to 24 hours differed between study 1 and study 2 for only two proteins: SAA1 $(p=0.003)$ and PAPPA $(p=0.004)$ (figure 1 and table 2).

While SAA1 and PAPPA increased in both studies at 24 hours posthypoglycemia, the percentage change increase was marked in response to milder prolonged hypoglycemia (study 1) and much less so in response to acute severe hypoglycemia (study 2) (SAA1: $246.5 \pm 136.0 \mathrm{vs}$ $7.2 \% \pm 5.9 \%$ baseline to 24 hours, controls study 1 vs study 2, p=0.003; PAPPA: $47.6 \pm 21.8$ vs $9.9 \% \pm 2.2 \%$ baseline to 24 hours, controls study 1 vs study 2, $\mathrm{p}=0.004$ ) (figure 1A,B). Both SAA1 and PAPPA were significant after Bonferroni correction.

Again, for subjects with T2D, there were no percentage change differences from baseline to 24 hours for any of the proteins between the two studies (figures 1-4).

\section{DISCUSSION}

This is the first study comparing the response of plasma AD-related proteins with differing lengths and severities of hypoglycemia. Here, we show that there are differential changes in AD-related proteins according to the nature of the hypoglycemic insult. The percentage change from baseline to hypoglycemia differed between study 1 (milder prolonged hypoglycemia for a 1-hour period) and study 2 (acute severe hypoglycemia) for 6 of the 11 proteins (SAA1, PAPPA, APOE, APOE2, APOE3 and APOE4) but only in control subjects. The percentage change from baseline to 24 hours differed between study 

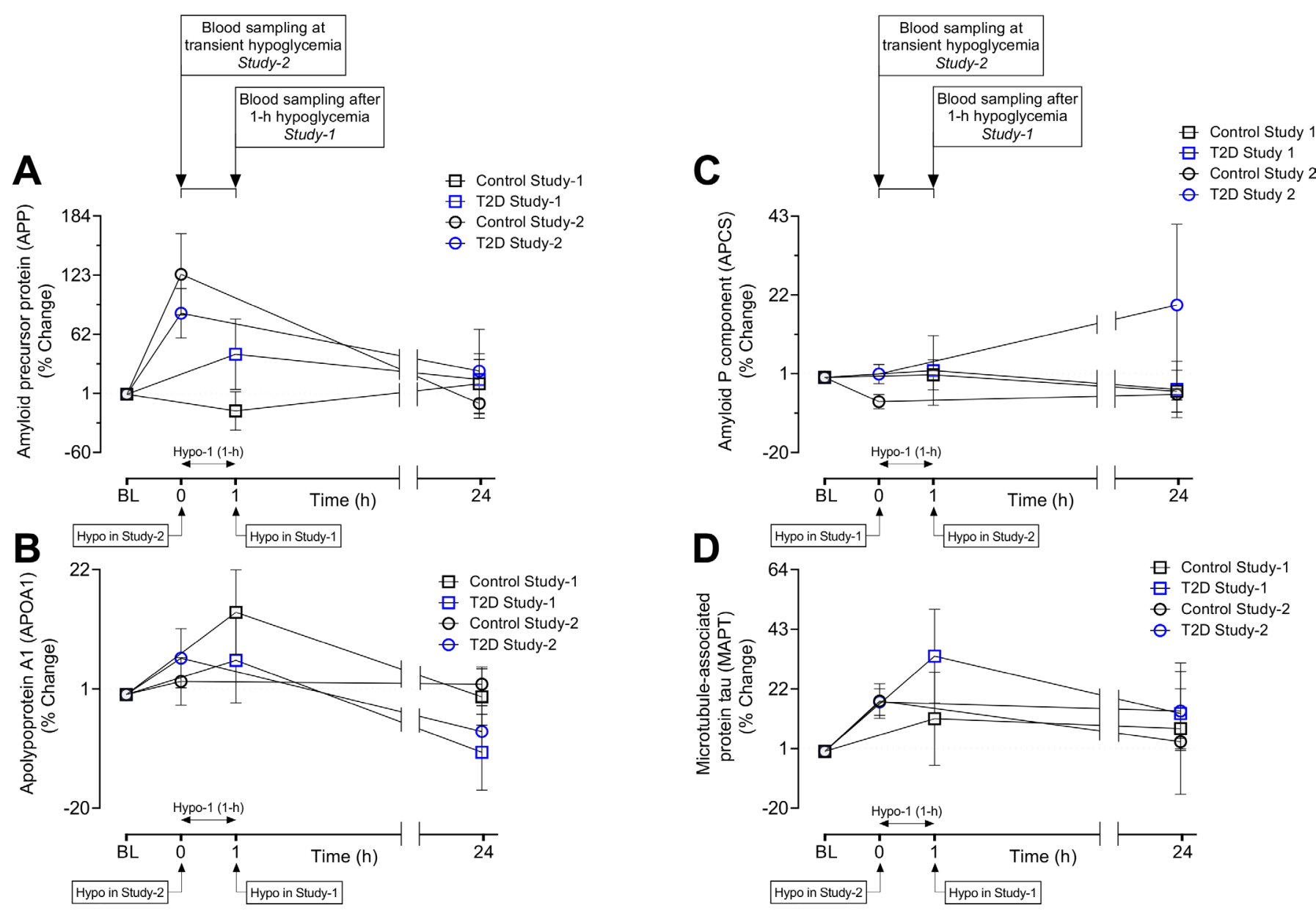

Figure 4 Alzheimer's disease (AD)-related proteins that did not differ as percentage changes in response to hypoglycemia in two different prospective studies in control subjects and subjects with type 2 diabetes (T2D). Line graphs showing changes as percentage of four AD-related proteins, amyloid precursor protein (APP) (A), apolipoprotein A1 (APOA1) (B), amyloid $P$ component (APCS) (C), microtubule-associated protein tau (MAPT) (D) from baseline to hypoglycemia and to 24 hours posthypoglycemia in study 1 (open white square, control and open blue square, T2D) and study 2 (open white circle, control and open blue circle, T2D). Baseline protein levels were normalized to 1 to show the $\%$ change from baseline to subsequent timepoints. There were no differential percentage changes for APP, MAPT, APCS or APOA1 either in control or in T2D from baseline to hypoglycemia or from baseline to 24 hours. Two-way arrows in the graphs indicate the duration of hypoglycemia for study 1. Data were present here as mean \% change of proteins \pm SEM. BL, baseline; Hypo, hypoglycemia.

1 and study 2 for only two proteins (SAA1 and PAPPA) and, again, only in control subjects.

It must be emphasized that the absolute changes in protein levels we reported previously in severe acute hypoglycemia (study 2$)^{13}$ are not contradictory to the differential relative changes we report here. Specifically, in absolute values at baseline in study 2, APP was elevated in T2D; at hypoglycemia, APCS was elevated in T2D while APP and noggin were elevated in controls; and at 24-hours, noggin had normalized in both cohorts, APP and MAPT normalized in controls but showed a below-baseline decrease in T2D. Therefore, the changes that occurred in response to hypoglycemia in T2D were similar in both study 1 and study 2 and were therefore not altered by the length or severity of the hypoglycemic insult. This is in marked contrast to the differential changes seen in controls between study 1 and study 2 . Differences in APP trends between the severity of the hypoglycemic insult (study 1 vs study 2) and between controls and T2D, may be due to differential clearance of the serum protein. APP is a membrane protein widely expressed, especially in the synapses of neurons, which is key in the development of AD pathogenesis. ${ }^{20} \mathrm{APP}$ consists of a single membrane-spanning domain that is cleaved by either alpha or beta secretase that may then be internalized $^{20}$; however, the kinetics of its clearance have not been determined nor whether these differ in T2D.

SAA1 is an acute-phase protein important in maintaining homeostasis in healthy tissues; however, increased expression in the brain has been reported in $\mathrm{AD} .{ }^{21}$ While most reports in the literature have considered SAA1 to be a proinflammatory mediator, more recent publications have questioned this paradigm, conversely purporting it to be an anti-inflammatory mediator. ${ }^{22}$

PAPPAs cleave IGF-binding proteins, and PAPPA-2 overexpression promotes $A \beta$ peptide accumulation in $\mathrm{AD} .{ }^{23}$ Increased circulatory PAPPA- 1 has been reported in subjects with T2D,${ }^{24}$ perhaps reflective of the common 
underlying protein misfolding pathophysiology. ${ }^{25}$ IGF proteins, once cleaved, negatively modulate the acute phase response, ${ }^{2627}$ and thus PAPPA also serves as an antiinflammatory mediator.

Studies are inconclusive as regards circulating APOE levels in $\mathrm{AD},{ }^{28}$ with some reporting an increase, ${ }^{29}$ some a decrease ${ }^{30}$ and some no change. ${ }^{31}$ APOE is a wellrecognized modulator of inflammation, suppressing the production of proinflammatory cytokines and converting proinflammatory M1 macrophages to an antiinflammatory M2 phenotype. $^{32}$

Taken together, these data suggest that control subjects are potentially able to mount a robust anti-inflammatory response to counter the presumably heightened inflammation that accompanies a prolonged, as opposed to an acute, hypoglycemic insult, but that the ability for subjects with T2D to mount such a response is blunted. Therefore, subjects with T2D have less capacity to regain homeostasis after such an insult, making them more susceptible to the negative sequelae of homeostatic perturbations. While T2D is recognized as an inflammatory pathology, in large measure there were few baseline differences compared with controls, but this may reflect the relatively short duration of disease in this cohort of patients with T2D.

The strengths of this study include inclusion of subjects with T2D having a short disease duration and being relatively treatment naïve and not on polypharmacy, characteristics that did not differ between studies and that the same study design with the hyperinsulinemic clamp protocol to hypoglycemia development was employed. As these were two separate studies, it was not possible to have the subjects undergo the two different hypoglycemic levels in random order in a randomized cross-over fashion. The age difference between studies may have contributed to the differences seen, with a blunting of the responses seen in study 2 . The relatively small subject numbers in each study cohort, for both subjects with T2D and control subjects, is the major limitation of this study as larger numbers may have revealed greater changes in plasma levels of amyloid-related proteins. However, in both studies, the subjects were subjected to significant, though differing, iatrogenic-induced hypoglycemic episodes, study 1 inducing prolonged though less severe hypoglycemia while study 2 induced severe and acute hypoglycemia; in both cases, it is highly likely that protein-level changes would have become evident, especially as the posthypoglycemia follow-up in both studies was to 24 hours. The panels used in the two studies were very similar, although not identical, and therefore some proteins present in the second panel were not available in the first. In addition, the protein panel analysis for each study was performed separately and not as part of a single study; therefore, relative change in protein level was undertaken here rather than absolute change to account for assay differences. A further limitation is that only circulatory protein levels were measured that may not be reflective of tissue levels. As subjects enrolled in these studies were, with a single exception, Caucasian, these results may not be generalizable to other ethnic populations. It should be noted that when correction for multiple testing using Bonferroni was used that only PAPPA and SAA1 remained significant, likely due to the small sample size leading to increased SD and the inherent conservatism of Bonferroni testing that may lead to false negative results.

In conclusion, these data support our hypothesis that milder prolonged hypoglycemia would lead to greater changes in AD-related proteins when compared with severe transient hypoglycemia. Interestingly, however, the differential changes were seen only in control subjects, suggesting that control subjects are able to mount a robust anti-inflammatory response to counteract the enhanced stress of prolonged hypoglycemia, but that subjects with T2D cannot.

Acknowledgements We thank the research nurses at the Diabetes Research Centre, Hull Royal Infirmary, for helping with blood sample collection.

Contributors ASMM: analyzed the data and wrote the manuscript; AA-Q: performed the clinical studies and edited the manuscript; TS: supervised clinical studies and data collection and contributed to the writing of manuscript; NK: performed statistical analyses; SLA: contributed to study design, data interpretation and the writing of the manuscript. AEB: analyzed the data and wrote the manuscript. All authors approved the final version of the manuscript. SLA is the guarantor of this work and, as such, had full access to all the data in the study and takes responsibility for the integrity of the data and the accuracy of the data analysis.

Funding The authors have not declared a specific grant for this research from any funding agency in the public, commercial or not-for-profit sectors.

Competing interests None declared.

Patient consent for publication Not required.

Ethics approval Trial 1 was approved by Yorkshire and the Humber Research Ethics Committee and performed from November 2011 to May 2013. Trial 2 was approved by the North West-Greater Manchester East Research Ethics Committee and performed from March 2017 to January 2018. Both trials were conducted in the Diabetes Centre at Hull Royal Infirmary according to the Declaration of Helsinki. All participants provided written informed consent.

Provenance and peer review Not commissioned; externally peer reviewed.

Data availability statement Data are available on reasonable request. All the data for this study will be made available on reasonable request to the corresponding author.

Supplemental material This content has been supplied by the author(s). It has not been vetted by BMJ Publishing Group Limited (BMJ) and may not have been peer-reviewed. Any opinions or recommendations discussed are solely those of the author(s) and are not endorsed by BMJ. BMJ disclaims all liability and responsibility arising from any reliance placed on the content. Where the content includes any translated material, BMJ does not warrant the accuracy and reliability of the translations (including but not limited to local regulations, clinical guidelines, terminology, drug names and drug dosages), and is not responsible for any error and/or omissions arising from translation and adaptation or otherwise.

Open access This is an open access article distributed in accordance with the Creative Commons Attribution Non Commercial (CC BY-NC 4.0) license, which permits others to distribute, remix, adapt, build upon this work noncommercially, and license their derivative works on different terms, provided the original work is properly cited, appropriate credit is given, any changes made indicated, and the use is non-commercial. See: http://creativecommons.org/ licenses/by-nc/4.0/.

ORCID ID

Alexandra E Butler http://orcid.org/0000-0002-5762-3917 


\section{REFERENCES}

1 Strachan MWJ, Reynolds RM, Marioni RE, et al. Cognitive function, dementia and type 2 diabetes mellitus in the elderly. Nat Rev Endocrinol 2011;7:108-14.

2 Biessels GJ, Staekenborg S, Brunner E, et al. Risk of dementia in diabetes mellitus: a systematic review. Lancet Neurol 2006;5:64-74.

3 Cukierman T, Gerstein HC, Williamson JD. Cognitive decline and dementia in diabetes--systematic overview of prospective observational studies. Diabetologia 2005;48:2460-9.

4 Gudala K, Bansal D, Schifano F, et al. Diabetes mellitus and risk of dementia: a meta-analysis of prospective observational studies. $J$ Diabetes Investig 2013;4:640-50.

5 Alzheimer's Association. 2014 Alzheimer's disease facts and figures. Alzheimers Dement 2014;10:e47-92.

6 Ott A, Stolk RP, van Harskamp F, et al. Diabetes mellitus and the risk of dementia: the Rotterdam study. Neurology 1999;53:1937-42.

7 Sims-Robinson C, Kim B, Rosko A, et al. How does diabetes accelerate Alzheimer disease pathology? Nat Rev Neurol 2010;6:551-9.

8 Zilkens RR, Davis WA, Spilsbury K, et al. Earlier age of dementia onset and shorter survival times in dementia patients with diabetes. Am J Epidemiol 2013;177:1246-54.

9 Yun S-M, Cho S-J, Jo C, et al. Elevation of plasma soluble amyloid precursor protein beta in Alzheimer's disease. Arch Gerontol Geriatr 2020;87:103995.

10 Bush Al, Beyreuther K, Masters CL. Beta A4 amyloid protein and its precursor in Alzheimer's disease. Pharmacol Ther 1992;56:97-117.

11 Chin SO, Rhee SY, Chon S, et al. Hypoglycemia is associated with dementia in elderly patients with type 2 diabetes mellitus: an analysis based on the Korea national diabetes program cohort. Diabetes Res Clin Pract 2016;122:54-61.

12 Al-Qaissi A, Papageorgiou M, Deshmukh H, et al. Effects of acute insulin-induced hypoglycaemia on endothelial microparticles in adults with and without type 2 diabetes. Diabetes Obes Metab 2019;21:533-40.

13 Moin ASM, Al-Qaissi A, Sathyapalan T, et al. Hypoglycaemia in type 2 diabetes exacerbates amyloid-related proteins associated with dementia. Diabetes Obes Metab 2021;23:338-349.

14 Kahal H, Halama A, Aburima A, et al. Effect of induced hypoglycemia on inflammation and oxidative stress in type 2 diabetes and control subjects. Sci Rep 2020;10:4750.

15 Kraemer S, Vaught JD, Bock C, et al. From SOMAmer-based biomarker discovery to diagnostic and clinical applications: a SOMAmer-based, streamlined multiplex proteomic assay. PLoS One 2011;6:e26332.

16 Suhre K, Arnold M, Bhagwat AM, et al. Connecting genetic risk to disease end points through the human blood plasma proteome. Nat Commun 2017;8:14357.
17 Ritchie ME, Phipson B, Wu D, et al. limma powers differential expression analyses for RNA-sequencing and microarray studies. Nucleic Acids Res 2015;43:e47.

18 Benjamini Y, Drai D, Elmer G, et al. Controlling the false discovery rate in behavior genetics research. Behav Brain Res 2001;125:279-84.

19 Dubowitz N, Xue W, Long Q, et al. Aging is associated with increased $\mathrm{HbA} 1 \mathrm{c}$ levels, independently of glucose levels and insulin resistance, and also with decreased $\mathrm{HbA} 1 \mathrm{c}$ diagnostic specificity. Diabet Med 2014;31:927-35.

20 Chen G-F, Xu T-H, Yan Y, et al. Amyloid beta: structure, biology and structure-based therapeutic development. Acta Pharmacol Sin 2017:38:1205-35.

21 Urieli-Shoval S, Linke RP, Matzner Y. Expression and function of serum amyloid $\mathrm{A}$, a major acute-phase protein, in normal and disease states. Curr Opin Hematol 2000;7:64-9.

22 Abouelasrar Salama S, De Bondt M, De Buck M, et al. Serum amyloid A1 (SAA1) revisited: restricted leukocyte-activating properties of homogeneous SAA1. Front Immunol 2020;11:843.

23 Mihelčić M, Šimić G, Babić Leko M, et al. Using redescription mining to relate clinical and biological characteristics of cognitively impaired and Alzheimer's disease patients. PLoS One 2017;12:e0187364.

24 Heidari B, Fotouhi A, Sharifi F, et al. Elevated serum levels of pregnancy-associated plasma protein-A in type 2 diabetics compared to healthy controls: associations with subclinical atherosclerosis parameters. Acta Med Iran 2015;53:395-402.

25 Akter K, Lanza EA, Martin SA, et al. Diabetes mellitus and Alzheimer's disease: shared pathology and treatment? Br J Clin Pharmacol 2011;71:365-76.

26 Spies M, Wolf SE, Barrow RE, et al. Modulation of types I and II acute phase reactants with insulin-like growth factor- $1 /$ binding protein-3 complex in severely burned children. Crit Care Med 2002;30:83-8.

27 Sukhanov S, Higashi Y, Shai S-Y, et al. IGF-1 reduces inflammatory responses, suppresses oxidative stress, and decreases atherosclerosis progression in apoE-deficient mice. Arterioscler Thromb Vasc Biol 2007;27:2684-90.

28 Irizarry MC. Biomarkers of Alzheimer disease in plasma. NeuroRx 2004;1:226-34.

29 Taddei K, Clarnette R, Gandy SE, et al. Increased plasma apolipoprotein E (apoE) levels in Alzheimer's disease. Neurosci Lett 1997:223:29-32.

30 Siest G, Bertrand P, Qin B, et al. Apolipoprotein E polymorphism and serum concentration in Alzheimer's disease in nine European centres: the ApoEurope study. ApoEurope group. Clin Chem Lab Med 2000;38:721-30.

31 Scacchi R, Gambina G, Ruggeri M, et al. Plasma levels of apolipoprotein $\mathrm{E}$ and genetic markers in elderly patients with Alzheimer's disease. Neurosci Lett 1999;259:33-6.

32 Zhang $\mathrm{H}$, Wu L-M, Wu J. Cross-talk between apolipoprotein E and cytokines. Mediators Inflamm 2011;2011:1-10. 